\title{
O CONTRATO INTERNACIONAL DE DISTRIBUIÇÃO NO DIREITO FRANCÊS E BRASILEIRO ${ }^{1}$
}

\author{
INTERNATIONAL DISTRIBUTION AGREEMENT UNDER FRENCH AND BRAZILIAN LAW
}

Roberta Ribeiro Oertel ${ }^{*}$

\begin{abstract}
Resumo:
A internacionalidade do conflito realça dificuldades específicas relativas à determinação da jurisdição competente e a lei aplicável ao contrato de distribuição. Há divergência entre os tribunais franceses quanto à natureza da responsabilidade civil do autor da ruptura abusiva do contrato. Estas dificuldades são acentuadas nos casos de aplicação do direito da União Europeia relativo à determinação da jurisdição internacional do contrato, ao contrário, dos litígios submetidos à arbitragem. Em relação ao direito brasileiro, o estudo revela que o princípio da autonomia das partes é bastante mitigado. Assim, as partes não podem escolher a lei aplicável ao contrato, se a disputa é submetida à autoridade judiciária brasileira. Entretanto, se o mesmo contrato é submetido à arbitragem, as partes podem designar o direito aplicável.

Palavras-chave: Direito Francês e Brasileiro. Direito Europeu. Direito Internacional Privado. Direito comparado. Litígio Internacional. Ruptura Abusiva. Responsabilidade Contratual e Extracontratual. Arbitragem.
\end{abstract}

\begin{abstract}
:
The internationality of the settlement of disputes emphasizes specific challenges relating to the determining the competent court and the applicable law to distribution agreements. There is a disagreement between French courts in relation of the nature of the liability in case of an abusive breach of contract. These difficulties arise in cases where EU law-based rules of international jurisdiction are applicable to the settlement of disputes, contrary to the disputes which are subject to arbitration. In Brazilian law, the study exposes a problem concerning the place of the principle of autonomy of will. The parties must not choose the applicable law to the contract if the dispute is submitted to a Brazilian court. On the contrary, in case the contract is subject to arbitration, the parties may determine the applicable law.
\end{abstract}

Keywords: French and Brazilian laws. European law. Private International Law. Comparative law. International conflict. Abusive breach. Contractual obligation. Torts. Arbitration.

Este artigo foi inspirado nas principais ideias tratadas na tese de doutoramento intitulada "Le contrat international de distribution en droits français et brésilien", defendida em Strasbourg em 20 de maio de 2014. A autora obteve a dupla titulação de acordo com os termos da Convenção de Coorientação firmada entre a Universidade de Strasbourg, França e a Universidade de São Paulo. Nesta última instituição, foi orientanda do Professor Paulo Borba Casella, Titular de Direito Internacional Público e Vice-Diretor da Faculdade de Direito da Universidade de São Paulo.

* Professora de Direito Internacional Privado e de Direito Europeu no Instituto Europeu de Administração Pública em Luxemburgo, Professora Convidada na Escola de Advocacia da Ordem dos Advogados de Paris e Advogada em São Paulo. 
Introdução

Os contratos de concessão comercial e de franquia empresarial são técnicas modernas de distribuição de mercadorias e serviços, amplamente utilizados no comércio interno e internacional. São, também, denominados de forma genérica de "contratos de distribuição", 2 pois é através da atividade do distribuidor (intermediário) que os produtos e serviços são também disponibilizados no mercado. Estes contratos resultam do aperfeiçoamento e da sofisticação do comércio sempre em busca de novas estratégias comerciais que permitam ao distribuidor alcançar sua clientela. Este último é, portanto, um "agente econômico"3 que exerce um papel fundamental no comércio contemporâneo.

A relação contratual entre distribuidor e fabricante é caracterizada por uma intensa colaboração entre eles. Assim, cabe ao fabricante concentrar seus esforços na fabricação de um produto ou na criação de um conceito de negócios, enquanto que ao distribuidor cabe revender tais produtos diretamente aos consumidores. Este poderá concentrar todos seus esforços comerciais na captação da clientela. Neste contexto, é necessária uma grande integração entre fabricante e distribuidor que permita o trabalho em conjunto de empresas juridicamente independentes, que desempenham funções diferentes e complementares.

Vale ressaltar que a expressão "contrato de concessão comercial” foi objeto de estudo na França na década de setenta. O eminente professor Claude Champaud definiu tal contrato

\begin{abstract}
como uma convenção pela qual um comerciante, chamado concessionário, coloca sua empresa de distribuição ao serviço de um comerciante ou industrial chamado concedente, para assegurar, exclusivamente, sobre um território determinado, durante um período limitado e sob a fiscalização do concedente, a distribuição de produtos cujo monopólio de revenda lhe é concedido. ${ }^{4}$
\end{abstract}

2 Na sua manifestação mais simples, a distribuição se exterioriza como contrato de fornecimento: o produtor obriga a fornecer certo volume de determinado produto e o revendedor obriga a adquiri-lo periodicamente. Para MARTINEK, Michael; SEMLER, Franz-Jörg; HABERMEIER, Stefan. Handbuch des Vertriebsrechts. 2. ed. München: Verlag C. H. Beck, 2003. p. 23: o direito da distribuição é um "direito da intermediação distributiva" ou "dos intermediários da distribuição" (Vertriebsrecht als Absatzmittlungsrecht).

3 LICARI, François-Xavier. La protection du distributeur intégré en droit français et allemand. Paris: Litec, 2002; DISSAUX, Nicolas. La qualification d'intermédiaire dans les relations contractuelles. Paris: LGDJ, 2007.

4 CHAMPAUD, Claude. La concession commerciale. Revue Trimestrielle de Droit Commerciale, Paris, 1963. p. 451. Ver também: MOUSSERON, Jean-Marc et al. Droit de la distribution. Paris: Litec, 1975; MOUSSERON, Jean-Marc. Producteurs, distributeurs, quelle concurrence? Paris: Litec, 1986; VIGNAL, Malaurie. Droit de la distribution. Paris: Sirey, 2012; FERRIER, Didier. Le droit de la distribution. 4. ed. Paris: Litec, 2006. 
No Brasil, o ilustre professor Rubens Requião inspirado no direito francês, referiu-se ao contrato de concessão comercial com exclusividade "como uma nova técnica de comercialização, de organização do mercado distribuidor de produtos industrializados ou de alta tecnicidade", 5 através do qual a

empresa produtora, [...], descentraliza sua atuação, deferindo
a outra empresa estranha a distribuição e colocação dos
seus produtos no mercado consumidor. Dessa forma, a
empresa produtora, organizando e disciplinando a rede de
concessionários, não se preocupa com o escoamento de
sua produção, descentralizando o setor comercial que é
complementar da atividade produtiva. ${ }^{6}$

Percebe-se através das duas definições que a empresa concedente tem o controle da relação contratual, pois ele organiza a cadeia de concessionários, instaurando uma política de revenda uniforme com vistas a estabelecer o mesmo padrão de qualidade tanto nos serviços quanto nas vendas. A rede de distribuição ganha uma imagem de marca própria e unitária que deverá ser difundida pelo concessionário recorrendo a marketing e outros meios para atrair os consumidores. Tem-se, assim, que o concessionário é um empresário autônomo juridicamente do produtor. Porém, ele fica submetido às instruções dadas pela empresa concedente no tocante à forma de execução da distribuição.

Paralelamente, tem-se ainda o contrato de franquia - outro tipo de contrato de distribuição - que apresenta algumas características da concessão comercial. Vale dizer que a relação jurídica entre franqueador e franqueado também é caracterizada pela intensa colaboração e integração entre eles, cabendo ao franqueador impor as regras de comercialização para todos os franqueados da rede, com o intuito de uniformizar o modo de revenda de bens e serviços ao cliente.

No entanto, a franquia diferencia-se da concessão comercial mediante duas características específicas, a saber: a obrigação de transmissão do know-how (savoir-faire) e o pagamento de royalties à empresa franqueada. ${ }^{7}$ Nas palavras do professor francês Didier Ferrier, a franquia é

um método de colaboração entre o franqueador, que desenvolveu uma atividade de distribuição de sucesso, e seus franqueados que desejam reiterar o negócio, dando àquele em contra partida uma remuneração $[\ldots]^{8}{ }^{8}$

5 REQUIÃO, Rubens. O contrato de concessão de venda com exclusividade (concessão comercial). Revista de Direito Mercantil, Rio de Janeiro, v. 7, p. 16-45, 1972.

6 Id. Ibid.

7 CASELLA, Paulo Borba. O fenômeno da franquia, da regulamentação comunitária à prática brasileira. Revista de Informação Legislativa, Brasília, v. 26, n. 103, p. 341-356, jul./set. 1989.

8 FERRIER, Didier. Le droit de la distribution... cit., p. 276. 
Tais características demonstram que a franquia não se confunde com o contrato de concessão comercial.

Nos últimos anos, observou-se na França e no Brasil o aumento significativo do número de franquias nacionais e internacionais, principalmente nos setores de vestuário, alimentação e hotelaria. Na França, alguns setores bem específicos têm grande destaque, tais como decoração de interiores e salões de cabeleireiro. ${ }^{9}$ Enquanto que no Brasil, franquias de curso de capacitação em diferentes áreas e de línguas estrangeiras têm crescido exponencialmente no mercado. ${ }^{10}$ Quanto à concessão comercial, tal técnica é principalmente utilizada na distribuição de bebidas, na revenda de veículos automotores e no setor de vestuário, acessórios de luxo e cosméticos nos dois países.

Outro aspecto importante dos contratos de concessão comercial e de franquia, refere-se à própria relação econômica entre fabricante e distribuidor. Não é a toa que a doutrina francesa denomina-os de "contratos de dependência", 11 pois o concessionário e o franqueado devem submeter-se à política de revenda imposta pelo promotor da cadeia de distribuição, ainda que continuem negociando por conta própria e em nome próprio, pois a empresa distribuidora é uma pessoa jurídica independente da empresa fabricante, criando, por conseguinte, uma forma de subordinação econômica em prol da atividade global de distribuição.

Acrescenta-se à relação de forte dependência entre distribuidor e fabricante, que a concessão comercial e a franquia são contratos atípicos no direito francês e brasileiro. Neste último, entretanto, o legislador regulamentou a concessão comercial de veículos automotores de via terrestre através da Lei n. 6.729 de 26 de dezembro de 1979, também conhecida na prática como Lei Ferrari, além do contrato de franquia empresarial através da Lei n. 8.955 de 15 de dezembro de $1994 .{ }^{12}$ A ausência de uma regulamentação específica

9 Dados coletados do site do Centre d'études internationales de la franchise. Disponível em: <www.ceipi. edu>.; Fédération européenne du franchisage. Disponível em: <www.eff-franchise.com>. Acesso em: 15 abr. 2013.

10 Dados coletados do site da Associação Brasileira de Franquia. Disponível em: <www.portaldofranchising. com.br>. Acesso em: 15 abr. 2013.

11 VIRASSAMY, Georges. Les contrats de dépendance. Paris: LGDJ, 1986.

12 Quanto aos contratos de distribuição no Código Civil Brasileiro, é importante esclarecer que não houve tipificação do contrato de concessão em geral nos arts. 710 e seguintes. O dispositivo cuidou exclusivamente do contrato de agência, como negócio que anteriormente se denominava contrato de representação comercial. A distribuição de que cogita o art. 710 é aquela que, eventualmente, pode ser autorizada ao agente mas nunca como revenda, e sempre como simples ato complementar do agenciamento. Na realidade, no contrato de agência, as mercadorias de propriedade do comitente são postas à disposição do agente-distribuidor para entrega aos compradores, mas tudo se faz em nome e por conta do representado. Segundo o Enunciado n. 31 adotado na Primeira Jornada de Direito Comercial, "contrato de distribuição previsto no art. 710 do Código Civil é uma modalidade de agência em que o agente atua como mediador ou mandatário do proponente e faz jus à remuneração devida por este, correspondente aos negócios concluídos em sua zona. No contrato de distribuição autêntico, o distribuidor comercializa diretamente o produto recebido do fabricante ou fornecedor, e seu lucro resulta das vendas que faz por sua conta e risco", (cf., PRIMEIRA JORNADA DE 
permite ao fabricante uma grande liberdade contratual, aumentando consideravelmente os encargos do distribuidor principalmente no âmbito da concessão comercial. O distribuidor, por sua vez, tende normalmente a aceitar as condições de execução do contrato impostas pelo fabricante, além de realizar investimentos financeiros para adequar-se às exigências de posicionamento da marca do fabricante no mercado.

A falta de um estatuto específico é sem dúvida um fator de complexidade. Mas soluções interessantes foram desenvolvidas pelos tribunais franceses e brasileiros, por exemplo, nos processos que envolvem abuso de direito de um dos contratantes em ações relativas à resilição unilateral do contrato. Vale dizer que, no direito francês, a expressão resilição unilateral é geralmente substituída pelo termo "ruptura do contrato", ${ }^{13}$ indicando também o término da relação contratual por vontade exclusiva de uma das partes.

Assim, a ruptura do contrato de distribuição pode ocorrer nos contratos por tempo determinado ou indeterminado, pois ninguém pode obrigar outrem a prorrogar uma convenção sistematicamente ou continuar o vínculo contratual de forma perpétua. Desse modo, a ruptura do contrato de distribuição é uma fatalidade, muitas vezes de difícil aceitação para o distribuidor porque vê seus investimentos prejudicados, embora seja uma prática muito frequente no comércio internacional.

É por esta razão que estudaremos a estrutura dos contratos de concessão comercial e de franquia no direito francês e brasileiro. As peculiaridades características destas duas técnicas contratuais continuam a seduzir os operadores do comércio, pois são formas contratuais flexíveis que se adaptam facilmente às necessidades do mercado. Contudo, suas estruturas complexas formadas por inúmeras obrigações típicas de outros contratos podem apresentar problemas ligados à sua natureza jurídica, que serão ressaltados mais claramente nos casos de ruptura abusiva do contrato interno e internacional de distribuição.

Nesta perspectiva, procederemos ao estudo da tipologia dos contratos de concessão comercial e de franquia com o objetivo de compreender melhor a relação que une fabricante e distribuidor. A partir daí, será possível verificarmos o regime jurídico destes contratos no direito francês e brasileiro, que são repetidamente colocados à prova quando se trata da ruptura do contrato (I).

A análise dos elementos fornecidos no direito interno francês e brasileiro possibilitará o desenvolvimento de questões ligadas aos contratos internacionais de distribuição. A determinação da competência judiciária internacional e do direito

DIREITO COMERCIAL, 23 e 24 de outubro de 2012. Brasília: Conselho da Justiça Federal, Centro de Estudos Judiciários, 2013).

13 FRADERA, Véra Maria Jacob de; TEPEDINO, Gustavo; SCHREIBER, André. La rupture du contrat. In: TRAVAUX DE L'ASSOCIATION HENRI CAPITANT. Rapport brésilien; la rupture du contrat. Paris: Société de Législation Comparée, 2005. t. IV, p. 695-712. 
aplicável são suscetíveis a dificuldades relacionadas à qualificação da convenção no caso do direito internacional privado francês. Quanto ao direito brasileiro, verificaremos que a análise comparativa da ruptura do contrato internacional viabilizará uma reflexão sobre o conteúdo das regras de Direito Internacional Privado em vigor, à luz de novas tendências no contexto internacional (II).

1. O contrato de distribuição no direito interno francês e brasileiro

O estudo sobre os contratos de concessão comercial e de franquia no direito interno francês e brasileiro é vislumbrado em dois momentos distintos.

Em primeiro lugar, através da análise da natureza jurídica dos contratos, das suas principais características e obrigações entre as partes, demonstraremos as diferenças existentes entre os contratos de concessão comercial e de franquia. Além disso, observaremos que a noção de contrato de concessão comercial e de franquia é divergente nos dois sistemas jurídicos (A).

Em segundo lugar, trataremos das condições de ruptura do vínculo contratual por vontade das partes nos contratos por prazo determinado e indeterminado, assim como suas consequências no âmbito da responsabilidade civil no direito francês e brasileiro (B).

A natureza jurídica dos contratos de distribuição

A natureza jurídica do contrato de concessão comercial e de franquia no direito francês e brasileiro é distinta, apesar de inúmeras convergências quanto às suas características primordiais e as obrigações das partes nos dois institutos.

No direito francês, os contratos de concessão comercial e de franquia são classificados de "contrato-quadro", ${ }^{14}$ que prevê a celebração de sucessivos contratos de venda denominados de "contrato de aplicação". ${ }^{15}$ A principal função do contrato-quadro de distribuição é organizar toda a relação jurídica entre o fabricante e o distribuidor, através da estipulação de cláusulas que determinam as principais obrigações das partes durante toda a vida do contrato. Trata-se de um contrato atípico cujo regime jurídico é regido por regras do direito das obrigações e da concorrência. Enquanto isso, o contrato de aplicação nada mais é que um contrato de compra e venda com regime jurídico próprio. Assim, estes dois contratos formam tão somente uma unidade econômica, exercendo assim uma função econômica no mercado. São, portanto, juridicamente independentes.

\footnotetext{
14 GATSI, Jean. Le contrat-cadre. Paris: LGDJ, 1996. POLLAUD-DULIAN, Frédéric; RONZANO, Alain. Le contrat-cadre, par-delà les paradoxes. Revue Trimestrielle de Droit Commerciale, Paris, Dalloz, 1996.

15 GATSI, Jean. Le contrat-cadre... cit., p. 7.
} 
Já no direito brasileiro, os contratos de concessão comercial e de franquia têm natureza jurídica de contratos mistos, ou seja, são contratos formados por diversas obrigações características de outros contratos ${ }^{16}$ Entretanto, podem ser contratos atípicos (art. 425 do Código Civil brasileiro) ${ }^{17}$ como no caso do contrato de concessão comercial em geral, ou típicos nos casos da distribuição de veículos automotores e da franquia empresarial que possuem regulamentação própria. Surge, assim, a figura contratual formada pelo contrato misto de distribuição que tem um caráter jurídico e econômico unitário, mesmo resultando da justaposição de obrigações típicas de outros contratos.

Nesse sentido, vale notar que a aplicação analógica da lei sobre a concessão de veículos automotores ou a lei sobre a franquia aos contratos atípicos de concessão comercial não é acolhida pela maioria da jurisprudência ${ }^{18} \mathrm{e}$ da doutrina brasileira. ${ }^{19}$ Desse modo, o regime jurídico da concessão comercial em geral é submetido às regras do direito das obrigações contidas no Código Civil brasileiro e a algumas regras da Lei Antitruste n. 12.529, de 30 de novembro de 2011, sobre cláusulas abusivas e de exclusividade.

No contrato de concessão comercial, a cláusula de exclusividade territorial e a de fornecimento de mercadorias é a principal característica da convenção no direito francês e brasileiro, contrariamente ao contrato de franquia que pode ou não conter a previsão de exclusividade de distribuição. Na verdade, as cláusulas essenciais à franquia são aquelas que estipulam a transferência de savoir-faire (know how), ${ }^{20}$ a utilização de licença de marca ou patente,,$^{21}$ bem como preveem o pagamento de royalties, ${ }^{22}$ de forma direita ou indireta, a cargo do franqueado que obteve direito ao uso de tecnologia de implantação e administração do negócio ou sistema operacional desenvolvido e detido pelo franqueador.

Tendo em vista a estrutura jurídica da relação criada entre concedente e concessionário e, entre franqueador e franqueado, o contrato de concessão comercial e de franquia podem gerar efeitos anticoncorrenciais no direito francês e europeu, devido

16 Tribunal de Justiça da Guanabara, Ap. civ. n. 79.863, j. 10.10.1972. Ver também sobre o assunto: GOMES, Orlando. Contratos. 26. ed. Rio de Janeiro: Ed. Forense, 2007. p. 121; VASCONCELOS, Pedro Pais de. Contratos atípicos. Coimbra: Almedina, 1995. p. 214; AZEVEDO, Álvaro Villaça de. Teoria geral dos contratos típicos e atípicos. 2. ed. São Paulo: Atlas, 2004. p. 141.

17 Art. 425. É lícito às partes estipular contratos atípicos, observadas as normas gerais fixadas neste Código.

18 STJ, Agravo Regimental no Ag. 43329/SP, Min. Eduardo Ribeiro, j. 15.03.1994, DJ: 16.05.1994, p. 11.766; STJ, REsp. n. 789.708-RS (2005/0174058-9), Min. Nancy Andrighi, j. 25.09.2006, DJ: 11.12.2006.

19 GRAU, Eros Roberto; FORGIONI, Paula Andrea. Restrição à concorrência, autorização legal e seus limites - Lei n. 8.884, de 1994 e Lei n. 6.729 (Lei Ferrari). Revista de Direito Mercantil, Rio de Janeiro, v. 114, p. 258-272, 1999.

20 AMARAL, Pedro. Savoir-faire e franquia sob a ótica do direito francês. Revista Trimestrial de Direito Civil, v. 32, p. 195-207, 2007.

21 LE TOURNEAU, Philippe. Les contrats de franchisage. Paris: Litec, 2003.

22 AMARAL, Pedro. Le contrat de franchise au Brésil. 2010. Tese (Doutorado) - Universidade de Montpellier I, Montpellier. 
ao abuso de posição dominante do fabricante em relação ao distribuidor. Para minimizar tais efeitos, o art. 330-3 do Código de Comércio francês obriga o fabricante a passar todas as informações necessárias sobre o negócio ao futuro distribuidor para que este aceite ou não a parceria ciente de todos os riscos inerentes à atividade. ${ }^{23}$ Esta obrigação précontratual de informação é exigida quando o contrato prevê a inclusão de uma cláusula de exclusividade ou de semiexclusividade. Nestes mesmos termos, uma regra semelhante é imposta ao franqueador, nos termos do art. $3^{\circ}$ da Lei sobre a franquia empresarial no direito brasileiro, quando este envia ao fraqueado a circular de oferta de franquia.

Enfim, o estudo das principais obrigações contratuais do contrato de concessão comercial e de franquia demonstra que tais contratos apresentam características $\operatorname{distintas}^{24} \mathrm{e}$, por isso, não se confundem. Porém, ambos têm a mesma natureza jurídica no direito francês, ou seja, são contratos-quadro e de aplicação, enquanto que no direito brasileiro são classificados de contratos mistos.

\section{A ruptura do contrato de distribuição}

É princípio do direito francês e brasileiro dos contratos a proibição de relações contratuais perpétuas nos contratos de longa duração. ${ }^{25}$

Sendo o contrato celebrado por tempo determinado ficam as partes obrigadas a executá-lo até o termo final. Ao fim do contrato, não existe direito à renovação compulsória do mesmo. Neste caso, os tribunais franceses e brasileiros verificam se não houve abuso por parte do fabricante que demonstra interesse em renovar o contrato ou dá indícios ao distribuidor de que irá fazê-lo. ${ }^{26}$ Se este, por sua vez, investe ainda no negócio

23 VIRASSAMY, G. La moralisation des contrats de distribution par la loi Doubin du 31 décembre 1989 (art. 1er). JCP E, II, 15809, 1990, p. 7. Segundo o autor, «En France, la loi n. 89-1008 du 31 décembre 1989 relative au développent des entreprises commerciales et industrielles et à l'amélioration de leur environnement économique, juridique et social, plus connue sous la dénomination «loi Doubin» a créé une obligation précontractuelle d'information à la charge du concédant, ainsi qu'à la charge du franchiseur. La finalité de l'obligation précontractuelle est de prévenir l'éventuel partenaire des risques et avantages de telle mesure ou acte envisagé, ainsi que sur toute circonstance ayant un rôle déterminant dans la décision de contracter».

24 MONTEIRO, António Pinto. Contratos de agência, de concessão e de franquia ("franchising"). In: ESTUDOS em Homenagem a Eduardo Correia. Boletim da Faculdade de Direito da Universidade de Coimbra, n. especial, p. 303-327, 1984. Do mesmo autor: Contratos de distribuição comercial. 2. ed. Coimbra: Almedina, 2004. Especialmente, p. 117.

25 BRITO, Maria Helena. O contrato de concessão comercial: descrição, qualificação e regime jurídico de um contrato socialmente típico. Coimbra: Almedina, 1990. p. 16.

26 A jurisprudência francesa já se posicionou em vários julgados neste sentido: Cass. com., 25 avr. $2001, D$. 2001, somm. 3227, n. D. Mazeaud; Cass. com., 4 janv. 1994, n. 91-18.170, Bull. civ. IV, n. 13, D. 1994, p. 3; Cass. com., 23 avr. 1985, Bull. civ. IV, n. 128; Cass. com., 30 nov. 1982, Bull. civ. IV, n. 392; Cass. com., 6 juin 2001, RJDA 2001, n. 1201; Cass. com., 23 mai 2000, RJDA 2000, n. 973, RTD civ. 2001, p. 137, obs. J. Mestre et B. Fages; T. com. Paris, 5 déc. 1997, n. Y. Marot. Quanto à doutrina francesa sobre o assunto, verificar: MESTRE, Jacques. Résiliation unilatérale et non-renouvellement dans les contrats de distribution. 
na esperança de prolongação da atividade poderá sofrer um prejuízo pecuniário devido ao fim súbito da relação contratual.

No caso dos contratos firmados por tempo indeterminado, a denúncia unilateral do contrato é lícita. ${ }^{27}$ Contudo, os tribunais controlam a existência de abuso de direito, ou seja, verificam se o fabricante deixou transcorrer um prazo razoável ou aviso prévio entre o momento da notificação da ruptura e o encerramento da atividade. ${ }^{28}$ Isso porque, a ruptura inesperada e brutal causa geralmente prejuízo ao distribuidor que pretende honrar pedidos realizados pelos seus clientes antes da denúncia, além de não permitir a distribuidor tempo hábil para encontrar outra parceria ou atividade. É por isso que os tribunais franceses e brasileiros verificam a "razoabilidade" do aviso prévio, levando em conta a duração da relação contratual, a natureza do negócio e o vulto dos investimentos realizados pelo distribuidor. ${ }^{29}$

Desse modo, a ausência ou insuficiência de aviso prévio razoável é interpretada pelos tribunais como contrária ao princípio da boa-fé. ${ }^{30}$ Isto porque, tal

In: La cessation des relations contractuelles d'affaires, 1997. Paris: PUAM. Este entendimento é também reiterado pelo Superior Tribunal de Justiça, nos seguintes termos (STJ, REsp. n. 493159, 2003/0001468-3, 19/10/2006, Rel. Min. Castro Filho, DJ: 13.11.2006, p. 241): "não constitui ato ilícito, gerador do devedor de indenizar, quando há disposição contratual assegurando às partes interromper o negócio de distribuição de bebidas, após atingido o termo final do contrato, não havendo, pois, que se falar em cláusula abusiva ou potestativa.". Quanto à doutrina brasileira: PAOLA, Leonardo Sperb de. Sobre a denúncia dos contratos de distribuição, concessão comercial e franquia. Revista Forense, São Paulo, v. 343, n. 94, p. 116-148, 1998.

27 BENABENT, Alain. Droit civil: les obligations. 7. ed. Paris: Montchrestien, 1999. p. 212; RIZZO, Frédéric. Regards sur la prohibition des engagements perpétuels. Droit et patrimoine, n. 78, p. 60, 2000.

28 Neste sentido é a posição do Tribunal de Justiça de São Paulo (SÃO PAULO. Tribunal de Justiça. Agravo de instrumento n. 96.551-4, j. 11.11.1998. JUIS Saraiva, São Paulo, n. 19. CD-ROM). Ver também dois julgados proferidos pelo Superior Tribunal de Justiça no qual foi julgado que é "princípio do direito contratual de relações continuativas que nenhum vínculo é eterno. Se uma das partes manifestou sua vontade de rescindir o contrato, não pode o Poder Judiciário impor a sua continuidade": Agravo Regimentar no Agravo de Instrumento n. 988.736 (2007/0281820-4) e Recurso Especial n. 534.105/MT, Rel. Min. Cesar Asfor Rocha, j. 19.12.2003. Quanto à jurisprudência francesa, verificar o acórdão da Cass. com. 28 nov. 2006, Bull. civ. IV, n. 234; D. 2007. 13, n. E. Chevrier no tocante à distribuição de veículos automotores.

29 BEAUCHARD, Jean. La nécessaire protection du concessionnaire et du franchisé à la fin du contrat. In: Mélanges à l'honneur de Philippe Le Tourneau. Paris: Dalloz, 2008. p. 40; MAZEAUD, Denis. Durées et ruptures. 2004, v. 1, RDCO, p. 129.

30 JUNQUEIRA DE AZEVEDO, Antonio. Contrato de distribuição - causa final dos contratos de trato sucessivo - resilição unilateral e seu momento de eficácia - interpretação contratual - negócio per relationem e preço determinável - conceito de "compra" de contrato e abuso do direito. Revista dos Tribunais, São Paulo, v. 826, p. 119-136, 2004. Sobre o princípio da boa-fé no direito brasileiro tem-se: FARO, Frederico Kastrup de. Boa-fé objetiva e dever de cooperação: uma análise sob as óticas do exercício da autonomia privada e da execução do contrato. Revista Trimestral de Direito Civil, São Paulo, v. 38, p. 3-39, 2009; MARTINS-COSTA, Judith. A boa-fé no direito privado. Revista dos Tribunais, São Paulo, p. 1999; e MARTINS-COSTA, Judith. A boa fé objetiva e o adimplemento das obrigações. Jurisprudência Brasileira, São Paulo, 2000, p. 11-36; RUBINSTEIN, Flávio. A bona fides como origem da boa-fé objetiva do direito brasileiro, Revista da Faculdade de Dreito da Universidade de São Paulo, São Paulo, v. 99, p. 573-658, 2004; DUARTE, Ronnie Prevss. Boa-fé, abuso do direito e o novo código civil brasileiro. Revista dos Tribunais, São Paulo, v. 817, p. 50-78, 2003. 
princípio é uma norma de comportamento que impõe às partes o dever de lealdade, confiança, respeito e consideração mútuos. ${ }^{31} \mathrm{O}$ distribuidor lesado pela ruptura brutal alega que houve abuso de direito da parte do fabricante e, por isso, requer em juízo perdas e danos decorrentes da falta de aviso prévio.

No direito francês, há previsão legal específica que sanciona a ruptura brutal de qualquer relação comercial existente, total ou parcial, por falta de aviso prévio nos termos do art. L. 442-6, I-5 ${ }^{\circ}$ do Código de Comércio francês. ${ }^{32}$ A responsabilidade do autor da ruptura brutal é qualificada de extracontratual, pois a infração cometida ao artigo mencionado é considerada um delito contra uma regra de direito da concorrência. ${ }^{33}$

Por sua vez, o direito brasileiro também condena a ruptura brutal do contrato de distribuição, pois considera como violação ao princípio da boa-fé objetiva (art. 422 do Código Civil) a denúncia imediata ou em curto prazo de tempo que causa prejuízo ao distribuidor. Ademais, prevê o art. 473 do Código Civil que nenhuma relação contratual pode ser rompida sem que a outra parte possa amortizar os investimentos realizados. Já nos contratos de concessão de veículos automotores, a Lei Ferrari permite a ruptura do

31 MAZEAUD, Denis. Loyauté, solidarité, fraternité: la nouvelle devise contractuelle? In: Mélanges Terré. Paris: Dalloz, 1999. p. 603-634: «des principes comme la loyauté, la confiance, la bonne foi sont les piliers de la relation contractuelle qui doit résister souvent des longues années»;

D'une exigence de bonne foi à un esprit de collaboration. Revue Trimestrielle de Droit Civil, Paris, p. 100, 1986. Na doutrina brasileira, indica-se o trabalho de NANNI, G. E. O dever de cooperação nas relações obrigacionais à luz do princípio constitucional da solidariedade. In: Temas relevantes do direito civil contemporâneo: homenagem ao Professor Renan Lotufo. São Paulo: Ed. Atlas, 2008. p. 283-321.

32 O art. L. 442-6-I-5 do Código de Comércio francês prevê:

"I.- Engage la responsabilité de son auteur et l'oblige à réparer le préjudice causé le fait, par tout producteur, commerçant, industriel ou personne immatriculée au répertoire des métiers:

$5^{\circ}$ De rompre brutalement, même partiellement, une relation commerciale établie, sans préavis écrit tenant compte de la durée de la relation commerciale et respectant la durée minimale de préavis déterminée, en référence aux usages du commerce, par des accords interprofessionnels. Lorsque la relation commerciale porte sur la fourniture de produits sous marque de distributeur, la durée minimale de préavis est double de celle qui serait applicable si le produit n'était pas fourni sous marque de distributeur. A défaut de tels accords, des arrêtés du ministre chargé de l'économie peuvent, pour chaque catégorie de produits, fixer, en tenant compte des usages du commerce, un délai minimum de préavis et encadrer les conditions de rupture des relations commerciales, notamment en fonction de leur durée. Les dispositions qui précèdent ne font pas obstacle à la faculté de résiliation sans préavis, en cas d'inexécution par l'autre partie de ses obligations ou en cas de force majeure. Lorsque la rupture de la relation commerciale résulte d'une mise en concurrence par enchères à distance, la durée minimale de préavis est double de celle résultant de l'application des dispositions du présent alinéa dans les cas où la durée du préavis initial est de moins de six mois, et d'au moins un an dans les autres cas;».

33 No direito francês, a responsabilidade do autor da ruptura abusiva do contrato de distribuição é extracontratual, sendo o contrato interno ou internacional. Existe, entretanto, uma possibilidade de excluir o regime extracontratual, se as partes estipularam uma cláusula de eleição de foro que especifica que todos os litígios oriundos do contrato serão submetidos ao tribunal escolhido e submetidos à lei do contrato. Neste caso, a matéria relativa à ruptura abusiva do contrato, ainda que seja uma forma de delito no direito francês, encontra-se na esfera de aplicação da cláusula de eleição de foro, sendo esta uma cláusula contratual. 
contrato por tempo indeterminado e determinado, mediante um aviso prévio legal (arts. 21 a 23). Caso a lei não seja respeitada, o próprio estatuto especial prevê as sanções cabíveis.

Além disso, a responsabilidade do autor da ruptura do contrato de distribuição no direito brasileiro é contratual e objetiva. ${ }^{34}$ Isto porque, o aviso prévio é uma obrigação contratual oriunda de certos deveres anexos ou acessórios às obrigações estipuladas no contrato escrito ou oral e que estão subentendidas no princípio da boa-fé objetiva. Este princípio é uma cláusula geral que indica um standart de comportamento dos contratantes durante a formação, execução e extinção do contrato que deve ser interpretada através da mútua confiança entre as partes.

Paralelamente, a jurisprudência francesa adota a mesma posição dos tribunais brasileiros, quanto ao dever de agir de boa-fé na extinção do vínculo contratual. Porém, o princípio da boa-fé no direito francês é uma norma de conduta que está além da esfera contratual. É considerado como uma norma moral que abrange o comportamento dos indivíduos independentemente da existência de uma relação jurídica. ${ }^{35}$

Em suma, é importante lembrar que toda esta análise feita a partir do estudo de diversos casos levados aos tribunais franceses e brasileiros, refere-se à ruptura do contrato interno de distribuição. Já o estudo comparativo dos contratos internacionais de distribuição requer um exame específico, tendo em vista outros aspectos ligados à determinação da competência judiciária internacional e às regras de direito aplicáveis.

2. O contrato internacional de distribuição no direito francês e brasileiro

O contencioso ligado aos litígios envolvendo a ruptura abusiva do contrato internacional de distribuição apresenta dificuldades específicas relativas à designação da jurisdição internacional competente $(\mathrm{A})$ e à determinação das regras de direito aplicáveis aos contratos de concessão comercial e franquia internacional (B).

34 Sobre o princípio da boa-fé objetiva verificar especialmente: NEGREIROS, Teresa. Fundamentos para uma interpretação constitucional do princípio da boa-fé. Rio de Janeiro: Renovar, 1998. p. 276; CORDEIRO, António Menezes. Da boa-fé no direito civil. 3. ed. Coimbra: Almedina, 1997. p. 641; WALD, Arnold. Le droit brésilien et le Code civil 2002. In: ARNOLD, Wald, (Org.). Code civil brésilien. Paris: Société de Législation Comparée, 2009. p. 24 e 25.

35 STOFFEL-MUNCK, Philippe. L'abus dans le contrat. Paris: LGDJ, 2000. p. 132: o autor explica que no direito francês «l'abus peut constituer soit une faute qui intéresse la sanction d'un comportement, soit l'exercice abusif d'une prérogative contractuelle ou d'une liberté. A ce titre, la bonne foi est au fond une norme extérieure au contrat, elle constitue un devoir moral plus qu'une obligation contractuelle proprement dit». 
A determinação da jurisdição competente no contrato de distribuição

Nos contratos internacionais do comércio, tais como o contrato de concessão comercial e de franquia, é muito comum que as partes estipulem a jurisdição competente através da inserção de uma cláusula de foro ou cláusula compromissória. Entretanto, a ausência de escolha prévia do tribunal competente obriga o juiz francês e brasileiro decidir da sua própria competência ou incompetência para julgar um litígio se as partes não optaram pela arbitragem. Para isso, o juiz aplicará as regras de direito internacional privado em matéria de conflitos de jurisdição.

No tocante às ações de ruptura brutal do contrato internacional de distribuição, tem-se visto que a validade da cláusula de eleição do foro é discutida quando o concessionário ou o franqueador sofrem prejuízo em razão do fim do contrato.

No direito francês, o distribuidor lesado pela ruptura brutal geralmente introduz a ação indenizatória no foro de sua residência com base no art. L. 442-6-I-5 ${ }^{\circ}$ do Código de Comércio francês, na tentativa de evitar a instauração do processo em um país estrangeiro de acordo com a cláusula de eleição de foro. Entretanto, a Corte Suprema Francesa interpretou vários casos de maneira negativa e afirmou que a cláusula de eleição de foro é válida ainda que uma regra de aplicação imediata pudesse ser aplicada pelo juiz francês. ${ }^{36}$ Isto significa que tal regra não tem o condão de afastar a competência de um tribunal estrangeiro. Tal solução se coaduna com a jurisprudência francesa em geral em matéria de validade da cláusula compromissória nos contratos de distribuição. ${ }^{37}$

Quanto ao direito brasileiro, a dificuldade existente refere-se à competência concorrente dos tribunais brasileiros nos termos do art. 88 do Código de Processo Civil,

36 Em relação à cláusula de eleição de foro: Cass. 1re civ. 22 octobre 2008, JCP G, n. 47, 19 nov. 2008, II, 10187, n. L. d'Avout; D. 2009, Jur. 200, n. F. Jault-Seseke; D. 2009, n. A. Huet, p. 684, D. 2008. AJ. 2790, obs. I. Gallmeister; RTD com. 2009, p. 646, obs. P. Delebecque; JDI, 2009, n. 2, 598, n. M.-N. JobardBachelier et F.-X. Train; RLDA, 2009, n. 36, n. G. Chabot, p. 63; RCDIP, 2009, n. H. Muir-Watt et D. Bureau, p. 25 et 27; CCC. 2008, comm. 270, n. M. Malaurie-Vignal; RDCO, 2009, p. 197, obs. M. BéharTouchais.

37 Em relação à arbitragem, a Corte de Cassação Francesa entende de maneira constante que (Civ. 1re civ. 8 juill. 2010, n. 09-67.013, Jurisdata n. 2010-012390, JCP E 2010, act. 406; JCP G 2010, p. 1286, n. J. Bégin; Rev. arb. 2010, p. 513, n. R. Dupeyré; D. 2010. 2884, obs. X. Delpech, n. M. Audit et O. Cuperlier; ibidem. 2933, obs. T. Clay; RCDIP, 2010, p. 743, n. D. Bureau et H. Muir-Watt): «la clause compromissoire visant tout litige ou différend né du contrat ou en relation avec celui-ci n'était pas manifestement inapplicable dès lors que la demande de Doga présentait un lien avec le contrat puisqu'elle se rapportait notamment aux conditions dans lesquelles il y avait été mis fin et aux conséquences en ayant résulté pour Doga, peu importe que des dispositions d'ordre public régissent le fond du litige». A Corte, então, concluiu que o recurso à arbitragem não deve ser excluído «du seul fait que des dispositions impératives, fussent-elles constitutives d'une loi de police, sont applicables au fond du litige».

Neste sentido: DERAINS, Yves. Les normes d'application immédiate dans la jurisprudence arbitrale internationale. In: Études offerts à Berthold Goldman. Paris: Litec, 1982. p. 29-46; e DERAINS, Yves. Les tendances de la jurisprudence arbitrale internationale. Journal du Droit International, Paris, 1993. p. 829. 
se o contrato é executado no Brasil ainda que as partes tenham estipulado no contrato uma cláusula de eleição de foro estrangeiro. Neste caso, a posição da jurisprudência brasileira é divergente quanto à validação ou não da cláusula de eleição de foro. ${ }^{38}$ Alguns tribunais são sensíveis ao argumento dos distribuidores que não desejam recorrer a um tribunal estrangeiro e alegam que foram obrigados a aceitar o contrato de adesão imposto pelo fornecedor. ${ }^{39}$ Mutatis mutandis, esse argumento é utilizado também quando há uma cláusula compromissória no contrato, mesmo se os tribunais não têm competência para julgar a validade e eficácia de tal cláusula (efeito negativo do princípio competênciacompetência).

Outra situação frequente no âmbito dos contratos internacionais do comércio é a falta de estipulação da jurisdição internacional competente pelas partes.

No direito da União Europeia, é importante lembrar que o Regulamento Bruxelas I sobre a determinação da competência internacional ${ }^{40}$ pode ser aplicado para a determinação do foro competente, se o réu for domiciliado em um dos Estados-membros da União Europeia. Tal regulamento não prevê regras específicas de conflito de jurisdição para o contrato intracomunitário de concessão comercial e de franquia, mas tão somente regras de conflito de jurisdição em matéria contratual (art. 5.1) e extracontratual (art. 5.3). O juiz deve assim determinar a regra aplicável para declarar o tribunal competente de acordo com uma dessas categorias. Vale ainda ressaltar que a regra de competência internacional em matéria contratual subdivide-se em duas outras, ou seja, uma regra específica para o contrato de compra e venda (art. 5.1.b, alínea primeira) e outra para o

38 Em favor da cláusula de eleição de foro estrangeiro: STJ, REsp. n. 2004/0022012-9, Min. Rel. Aldir Passarinho Junior, j. 04.03.2010, DJ: 29.03.2010.

39 O Superior Tribunal de Justiça (Embargos de declaração nos embargos de declaração no Recurso Especial n. 2009/0203571-7, Rel. Ministra Nancy Andrighi, j. 15/03/2011; DJ: 25/03/2011) também entendeu que "a cláusula de eleição de foro estrangeiro não afasta a competência internacional concorrente da autoridade brasileira, nas hipóteses em que a obrigação deva ser cumprida no Brasil (art. 88, II, do CPC)”. Neste sentido, ver também: TJRS, AgIn. n. 70023968704, CMA CGM do Brasil Agência Marítima LTDA c/ Big Dutchman Brasil LTDA, Des. Rel. Judith dos Santos Mottecy, j. 05.06.2010. Quanto à doutrina brasileira, vários autores concordam sobre a necessidade de autonomia da cláusula de eleição de foro, tais como: ARAUJO, Nadia de. Direito internacional privado. 5. ed. Rio de Janeiro: Renovar, 2011. p. 246; CARNEIRO, Athos Gusmão. Jurisdição e competência. 14. ed. São Paulo: Saraiva, 2005. p. 55; FRANCESCHINI, José I. G. A Lei e o foro de eleição em tema de contratos internacionais. In: RODAS, J. Grandino (Org.). Contratos internacionais. 2. ed. São Paulo: Revista dos Tribunais, 1995. p. 55.

40 Regulamento (CE) n. 44/2001 do Conselho de 22 de Dezembro de 2001 relativo à competência judiciária, ao reconhecimento e à execução de decisões em matéria civil e comercial (JO L 12 de 16.1.2001, p. 1). Vale dizer que este Regulamento foi substituído pelo novo Regulamento conhecido como Bruxelas I-bis: Regulamento (UE) n. 1215/2012 do Parlamento Europeu e do Conselho de 12 de dezembro de 2012, relativo à competência judiciária, ao reconhecimento e à execução de decisões em matéria civil e comercial (reformulação), JO L 351/1. Este Regulamento entrou em vigor no dia 10 de janeiro de 2015. Sobre a refonte do instrumento: GAUDEMET-TALLON, Helene. Compétence et exécution des jugements en Europe. 4. ed. Paris: LGDJ, 2010; GAUDEMET-TALLON, Helene; KESSEDJIAN, Catherine. La refonte du règlement Bruxelles I. Revue Trimestrielle de Droit Européen, Paris, p. 435-454, 2013. 
contrato de prestação de serviço (art. 5.1.b, alínea segunda). Entretanto, inúmeras decisões proferidas pelos tribunais franceses basearam-se na aplicação do critério da "localização da prestação característica" do contrato de distribuição, sendo esta no contrato de concessão comercial exclusiva a obrigação do concedente de fornecer mercadorias ao concessionário.

Recentemente, o Tribunal de Justiça da União Europeia teve a oportunidade de interpretar a aplicação do Regulamento Bruxelas I, através do mecanismo de reenvio prejudicial. ${ }^{41} \mathrm{O}$ Tribunal de Verviers (Bélgica) reenviou duas questões prejudiciais ao Tribunal de Luxemburgo no intuito de: (a) saber qual dispositivo deve ser aplicado para a determinação da competência internacional do contrato de concessão comercial e, (b) obter esclarecimentos sobre as características do contrato de concessão de venda exclusiva. ${ }^{42}$ No caso, tratava-se de um contrato verbal firmado entre uma empresa francesa (concedente) e uma empresa belga (concessionária) para a revenda de bebidas na Bélgica. Segundo a decisão proferida pelo Tribunal de Justiça, o tribunal competente para julgar litígios relacionados ao contrato de concessão exclusiva de venda deve ser designado através da aplicação do art. 5.1.b, alínea segunda. Isto significa que a concessão comercial poderá ser assimilada ao contrato de prestação de serviço, pois a exclusividade de revenda sobre um território é uma vantagem econômica para o concessionário, constituindo assim um tipo de remuneração. A remuneração é uma característica essencial dos contratos de prestação de serviço na interpretação do Tribunal de Justiça em julgado anterior. ${ }^{43}$

Por último e em relação ao direito brasileiro, é importante lembrar que se o contrato internacional não dispor sobre o tribunal competente em caso de litígio futuro, o juiz brasileiro deverá declarar sua competência com base no art. 88 do Código de Processo Civil. ${ }^{44}$ Lembrando ainda que no âmbito do Mercosul, o Protocolo de Buenos Aires dispõe sobre a competência internacional em matéria civil e comercial, prevendo regras gerais para a determinação da competência, bem como regras sobre a escolha de foro.

$41 \quad$ O reenvio prejudicial é um procedimento previsto no art. 267 do Tratado sobre o Funcionamento da União Europeia, que permite ao juiz nacional de qualquer instância enviar questões ao Tribunal de Justiça da União Europeia sobre a interpretação ou a validade das normas da União Europeia.

42 CJUE, affaire C-9/12 du 19 décembre 2013, Corman-Collins SA contra La Maison du Whisky SA. Sobre esta decisão: OERTEL, Roberta Ribeiro. La détermination de la juridiction compétente du contrat international de concession exclusive. L'observateur de Bruxelles, Bruxelas, n. 98, p. 36-38, out. 2014.

43 CJCE, 23 avril 2009, aff. C-533/07, Fondation Falco c/ Gisela Weller.

44 "Art. 88. É competente a autoridade judiciária brasileira quando:

I - o réu, qualquer que seja a sua nacionalidade, estiver domiciliado no Brasil;

II - no Brasil tiver de ser cumprida a obrigação;

III - a ação se originar de fato ocorrido ou de ato praticado no Brasil.

Parágrafo único. Para o fim do disposto no n. I, reputa-se domiciliada no Brasil a pessoa jurídica estrangeira que aqui tiver agência, filial ou sucursal." 
A determinação do direito aplicável ao contrato de distribuição

O Direito Internacional Privado francês e brasileiro adotam regras distintas em matéria de Direito Internacional Privado aplicáveis aos contratos internacionais de concessão comercial e de franquia empresarial.

É importante ressaltar que o Direito Internacional Privado francês é constituído pelas regras do Regulamento Roma I sobre a lei aplicável às obrigações contratuais $^{45}$ e Roma II sobre a lei aplicável às obrigações extracontratuais. ${ }^{46}$ Estes dois instrumentos de origem comunitária adotam o sistema dualista no qual é permitido às partes escolherem a legislação aplicável ao contrato internacional e, na ausência de escolha, os dois instrumentos indicam critérios de determinação do direito aplicável para alguns contratos especiais por meio de critérios de conexão objetivos.

Assim, o Regulamento Roma I prevê em seu art. 4. 1. "e" e 4. 1. "f" regras especiais de conexão para o contrato de franquia e de distribuição respectivamente. ${ }^{47} \mathrm{Em}$ ambos os casos, tais contratos serão regulados pela lei do país em que o franqueado ou o distribuidor tiver sua residência habitual, se as partes não indicaram previamente a lei aplicável ao contrato. Estas regras foram introduzidas no Regulamento Roma I, pois houve muita divergência dos tribunais europeus nos últimos anos quanto à determinação da lei aplicável aos contratos de distribuição. Na verdade, o sistema da Convenção de Roma sobre a lei aplicável às obrigações contratuais vigentes até a aplicação do Regulamento Roma I, adotou como critério principal para a determinação da legislação aplicável o princípio de proximidade no qual o juiz deve verificar se o conjunto das circunstâncias do caso concreto apresenta uma conexão manifestamente mais estreita com um país para que a lei deste país seja aplicada.

O princípio de proximidade inspirou vários juristas do continente americano nos trabalhos que culminaram com a elaboração da Convenção do México sobre o direito aplicável aos contratos internacionais de 1994, no âmbito da Convenção Interamericana de Direito Internacional Privado, que também consagrou o sistema dualista da Convenção de Roma no âmbito da Comunidade Europeia. A Convenção do México foi assinada pelo Brasil, mas não foi ainda ratificada. A adesão do Brasil permitiria que o princípio da

45 Regulamento (CE) n. 593/2008 do Parlamento Europeu e do Conselho, de 17 de Junho de 2008, sobre a lei aplicável às obrigações contratuais (OJ L 177, 4.7.2008, p. 6-16).

46 Regulamento (CE) n. 864/2007 do Parlamento Europeu e do Conselho de 11 de Julho de 2007, relativo à lei aplicável às obrigações extracontratuais (OJ L 199/40, 31.7.2007).

47 Sobre os critérios de conexão adotados no Regulamento Roma I: FERRARI, Franco. La loi applicable à défaut de choix par les parties selon l'article 4 de la proposition de règlement Rome I. Travaux du Comité Français de Droit International Privé, Paris, 2006-2008, p. 115-149 e Quelques remarques sur le droit applicable aux obligations contractuelles en l'absence de choix des parties, art. 4 du règlement Rome I. Revue Critique de Droit International Privé, Paris, 2009. p. 459. 
autonomia da vontade pudesse ser novamente reintegrado ao sistema de regras de direito internacional privado brasileiro.

Atualmente, a Lei de Introdução às Normas do Direito Brasileiro (a antiga Lei de Introdução ao Código Civil Brasileiro de 1942) não contempla o princípio da autonomia das partes nos contratos internacionais que são submetidos ao juiz de direito. ${ }^{48}$ A única possibilidade existente no direito brasileiro refere-se aos contratos submetidos à arbitragem em virtude do art. 2 da Lei n. 9.307, de 23 de setembro de 1996. No mais, a única regra de conflito de leis existente no direito internacional privado brasileiro admite que os contratos internacionais sejam submetidos a lex loci contractus ou lex loci celebrationis (art. 9). ${ }^{49}$ Sendo assim, não há regra específica para o contrato de concessão comercial ou de franquia como no direito comunitário.

A prática do comércio internacional tem demonstrado que o contrato de distribuição é redigido de acordo com a legislação que será aplicada ao contrato em caso de litígio e tal menção é expressa no contrato. Sendo o contrato proposto pelo fabricante ao distribuidor, geralmente o regime jurídico é aquele do país no qual o fabricante tem sua residência habitual. Além disso, é do interesse do fabricante que todos os contratos da cadeia de distribuição possam ser regidos pela mesma legislação, ainda mais se for aplicada a teoria do contrato-quadro de distribuição do direito francês. Devido à autonomia jurídica que gozam o contrato-quadro e o contrato de aplicação, leis diferentes podem ser aplicadas para cada contrato. ${ }^{50}$ Por esta razão, tem-se que no âmbito do direito internacional privado francês a teoria do contrato-quadro e dos contratos de aplicação pode apresentar situações complexas para os operadores do comércio internacional. Uma solução viável para evitar eventuais dificuldades futuras é a determinação prévia no contrato-quadro de uma cláusula que indique a jurisdição competente e a lei aplicável ao conjunto de contratos em caso de litígio.

No direito brasileiro, a teoria do contrato misto de distribuição revela que as inúmeras prestações que compõem a convenção formam uma operação econômica

48 DOLINGER, Jacob; TIBÚRCIO, Carmen. Vade Mecum de direito internacional privado. Rio de Janeiro: Renovar, 1994.

49 "Art. 9o: Para qualificar e reger as obrigações, aplicar-se-á a lei do país em que se constituírem.

$\S 1$ 1 Destinando-se a obrigação a ser executada no Brasil e dependendo de forma essencial, será esta observada, admitidas as peculiaridades da lei estrangeira quanto aos requisitos extrínsecos do ato. $\S 2$ - A obrigação resultante do contrato reputa-se constituída no lugar em que residir o proponente."

50 Sabe-se que o princípio da autonomia das partes no direito internacional privado permite designar a lei ou às regras de direito aplicáveis ao todo ou a uma parte do contrato internacional de distribuição. Esta é uma faculdade ofertada aos contratantes através da técnica do fracionamento (dépeçage). Porém, se as partes não escolheram o direito aplicável de forma clara e incontroversa nos dois contratos, tem-se que as regras de conflito de leis diferentes sejam aplicadas para cada um deles. Isto porque, o contrato de aplicação tem a natureza jurídica de um contrato de compra e venda de trato sucessivo, enquanto que o contrato-quadro é somente um arcabouço jurídico que organiza a política de vendas e as obrigações das partes. 
indivisível, evitando, assim, as dificuldades mencionadas em relação ao contrato-quadro no Direito Internacional Privado francês.

No entanto, outras dificuldades - não menos relevantes - são observadas relativamente ao sistema de regras de Direito Internacional Privado brasileiro, quando da análise da jurisprudência referente à ruptura do contrato de distribuição.

Em primeiro lugar, observou-se que a validade da cláusula de eleição de foro nos contratos internacionais de distribuição pode ser questionada pela autoridade judiciária brasileira, principalmente se a parte brasileira alegar que se trata de um contrato de adesão no qual a eleição do foro estrangeiro foi imposta pelo outro contratante. Desse modo, entendemos que tal situação precisa de enquadramento jurídico mais rigoroso para dar mais segurança jurídica aos contratos internacionais. Uma solução viável para remediar a situação é a adoção de dispositivos legais na reforma do Código de Processo Civil brasileiro, que possam impedir que a competência concorrente da justiça brasileira anule a cláusula de eleição de foro estrangeiro. Outra solução possível seria a ratificação da Convenção de Haya sobre os acordos de eleição de foro de 2005 no âmbito internacional.

Em segundo lugar, constatou-se que o princípio da autonomia das partes não é mais consagrado no Direito Internacional Privado brasileiro, exceto quando o contrato prevê a instauração da arbitragem para dirimir eventuais litígios. Esta posição do direito brasileiro revela-se contrária à prática dos contratos internacionais do comércio em vários sistemas jurídicos, como o direito francês, que permitem a livre escolha da lei aplicável ao contrato de concessão comercial e de franquia sujeitos também à jurisdição estatal.

A prerrogativa conferida aos contratantes quanto à escolha da lei aplicável aos contratos internacionais de distribuição permite aos contratantes a aplicação de uma regra que corresponde melhor às obrigações estipuladas na convenção. É por este motivo que consideramos de suma importância a readmissão do princípio da autonomia das partes no direito brasileiro. Um primeiro passo, neste sentido, seria a ratificação da Convenção do México sobre o direito aplicável ao contrato internacional pelo Brasil no âmbito interregional. ${ }^{51}$

No âmbito internacional, assume relevância significativa o princípio da autonomia das partes por meio de estudos específicos relativos aos contratos internacionais que visam melhorar a coordenação internacional dos diversos sistemas jurídicos e, sobretudo, reforçar a previsibilidade jurídica de soluções através da aplicação deste princípio. É o caso, por exemplo, do projeto sobre os Princípios de Haia sobre o direito aplicável aos contratos internacionais desenvolvidos pela Conferência de Haia de

CASELLA, Paulo Borba. Mercosur: Intégration économique et harmonisation juridique. Revista da Faculdade de Direito da Universidade de São Paulo, São Paulo, v. 90, p. 327-337, 1995. 
Direito Internacional Privado. Por último, ressalta-se também o guia sobre os Acordos Internacionais de Franquia Principal adotados pelo Unidroit. ${ }^{52}$

\section{Conclusão}

A análise comparativa dos contratos de concessão comercial e de franquia no direito francês e brasileiro permitiu destacar inúmeras dificuldades nas quais os operadores do direito são confrontados na prática do comércio internacional, com ênfase na questão relativa ao conteúdo do direito aplicável nas ações de indenização pela ruptura abusiva do contrato movida pelo distribuidor contra o fabricante. Neste momento, ambas as partes têm interesse em aplicar o direito que poderá lhes conferir uma proteção mais vantajosa.

Quando o contrato de distribuição é celebrado segundo o direito francês, as partes podem escolher o direito aplicável ao contrato. Como frequentemente a convenção é proposta pelo fabricante responsável pela rede de distribuição, a cláusula de determinação do direito aplicável é imposta ao distribuidor. A tendência, neste caso, é que a legislação escolhida seja a da residência habitual do fabricante, ou seja, do contratante que organiza e planeja todos os contratos de distribuição. É uma questão de segurança e previsibilidade para o fabricante que verá aplicado ao contrato as mesmas regras de direito cujo conteúdo é conhecido previamente.

Porém, se o contrato não comporta uma estipulação sobre o direito aplicável, são as regras de conflito de leis emanadas do direito comunitário que serão aplicadas ao caso concreto. O legislador europeu optou pela adoção de um critério de conexão objetivo e fixo para o contrato de distribuição e de franquia no intuito de preservar a segurança jurídica dos contratantes, tendo em vista uma grande divergência de pontos de vista sobre o assunto na doutrina e jurisprudência europeias. Optou-se, então, pela lei do país da residência habitual do distribuidor e do franqueado. Essa solução aparenta favorecer o concessionário e o franqueado, pois se presume que estes conheçam o próprio sistema jurídico, favorecendo a aplicação do juiz do foro. Na realidade, entretanto, o conteúdo do direito pode ser menos benéfico que aquele disposto na lei do país da residência do fabricante.

Quanto ao direito brasileiro, o critério de conexão adotado para os contratos internacionais determina que a lei aplicável é aquela onde as obrigações são constituídas. Não é possível que as partes escolham livremente o direito aplicado à convenção.

52 CASELlA, Paulo Borba. Utilização no Brasil dos Princípios Unidroit relativos aos contratos comerciais internacionais. In: CASELLA, Paulo Borba (Org.). Contratos internacionais e direito econômico no MERCOSUL. São Paulo: LTr, 1996. p. 104. 
Entendemos que os contratantes possam designar o direito ou ainda regras de soft law $w^{53}$ para reger as obrigações contratuais nos contratos de distribuição. Na ausência de determinação do regime jurídico, a lei do país de residência do fabricante poderá ser aplicada ao contrato.

Luxemburgo, 24 de abril de 2015.

\section{Referências}

AMARAL, Pedro. Savoir-faire e franquia sob a ótica do direito francês. Revista Trimestral de Direito Civil, v. 32, p. 195-207, 2007.

. Le contrat de franchise au Brésil. 2010. Tese (Doutorado) - Universidade de Montpellier I, Montpellier, 2010.

ARAUJO, Nadia de. Direito internacional privado. 5. ed. Rio de Janeiro: Renovar, 2011.

AZEVEDO, Álvaro Villaça de. Teoria geral dos contratos típicos e atípicos. 2. ed. São Paulo: Atlas, 2004.

BEAUCHARD, Jean. La nécessaire protection du concessionnaire et du franchisé à la fin du contrat. In: Mélanges à l'honneur de Philippe Le Tourneau. Paris: Dalloz, 2008. p. 40-56.

BENABENT, Alain. Droit civil: les obligations. 7. ed. Paris: Montchrestien, 1999.

BRITO, Maria Helena. O contrato de concessão comercial: descrição, qualificação e regime jurídico de um contrato socialmente típico. Coimbra: Almedina, 1990.

CARNEIRO, Athos Gusmão. Jurisdição e competência. 14. ed. São Paulo: Saraiva, 2005.

CASELLA, Paulo Borba. Mercosur: Intégration économique et harmonisation juridique. Revista da Faculdade de Direito da Universidade de São Paulo, São Paulo, v. 90, p. 327-337, jan./dez. 1995.

. O fenômeno da franquia, da regulamentação comunitária à prática brasileira. Revista de Informação Legislativa, Brasília, v. 26, n. 103, p. 341-356, jul./set. 1989.

. Arbitragem internacional e boa-fé das partes contratantes. Revista dos Tribunais, São Paulo, v. 80, n. 668, p. 239-241, 1991.

- Utilização no Brasil dos princípios Unidroit relativos aos contratos comerciais internacionais. In: CASELLA, Paulo Borba (Org.). Contratos internacionais e direito econômico no MERCOSUL. São Paulo: LTr, 1996. p. 104.

$53 \quad$ STRENGER, Irineu. La notion de lex mercatoria en droit de commerce international, Recueil des Cours de l'Académie de Droit International de La Haye, Haia, t. 227, p. 209-335, 1991-II. 
CHAMPAUD, Claude. La concession commerciale. Revue Trimestrielle de Droit Commerciale, Paris, 1963.

CORDEIRO, António Menezes. Da boa fé no direito civil. 3. ed. Coimbra: Almedina, 1997.

DERAINS, Yves. Les normes d'application immédiate dans la jurisprudence arbitrale internationale. In: Études offerts à Berthold Goldman. Paris: Litec, p. 29-46.

. Les tendances de la jurisprudence arbitrale internationale. Journal du Droit International, Paris, 1993, p. 829.

DISSAUX, Nicolas. La qualification d'intermédiaire dans les relations contractuelles. Paris: LGDJ, 2007.

DOLINGER, Jacob; TIBÚRCIO, Carmen. Vade Mecum de direito internacional privado. Rio de Janeiro: Renovar, 1994.

DUARTE, Ronnie Prevss. Boa-fé, abuso do direito e o novo código civil brasileiro. Revista dos Tribunais, São Paulo, v. 817, p. 50-78, 2003.

FARO, Frederico Kastrup de. Boa-fé objetiva e dever de cooperação: uma análise sob as óticas do exercício da autonomia privada e da execução do contrato. Revista Trimestral de Direito Civil, São Paulo, v. 38, p. 3-39, 2009.

FERRARI, Franco. La loi applicable à défaut de choix par les parties selon l'article 4 de la proposition de règlement Rome I. Travaux du Comité Français de Droit International Privé, Paris, p. 115-149, 2006-2008.

. Quelques remarques sur le droit applicable aux obligations contractuelles en l'absence de choix des parties, art. 4 du règlement Rome I. Revue Critique de Droit International Privé, Paris, 2009.

FERRIER, Didier. Le droit de la distribution. 4. ed. Paris: Litec, 2006.

FOUCHARD, Philippe; GAILLARD, Emmanuel; GOLDMAN, Berthold. Traité de l'arbitrage commercial international. Paris: Litec, 1996.

FRADERA, Véra Maria Jacob de; TEPEDINO, Gustavo; SCHREIBER, André. La rupture du contrat. In: TRAVAUX DE L'ASSOCIATION HENRI CAPITANT. Rapport brésilien; la rupture du contrat. Paris: Société de Législation Comparée, 2005. t. IV, p. 695-712.

FRANCESCHINI, José I. G. A Lei e o foro de eleição em tema de contratos internacionais. In: RODAS, J. Grandino (Org.). Contratos Internacionais. 2. ed. São Paulo: Revista dos Tribunais, 1995.

GATSI, Jean. Le contrat-cadre. Paris: LGDJ, 1996.

GAUDEMET-TALLON, Helene. Compétence et exécution des jugements en Europe. 4. ed. Paris: LGDJ, 2010. 
GAUDEMET-TALLON, Helene; KESSEDJIAN, Catherine. La refonte du règlement Bruxelles I. Revue Trimestrielle de Droit Européen, Paris, p. 435-454, 2013.

GOMES, Orlando. Contratos. 26. ed. Rio de Janeiro: Ed. Forense, 2007.

GRAU, Eros Roberto; FORGIONI, Paula Andrea. Restrição à concorrência, autorização legal e seus limites - Lei n. 8.884, de 1994 e Lei n. 6.729 (Lei Ferrari). Revista de Direito Mercantil, Rio de Janeiro, v. 114, p. 258-272, 1999.

GUYENOT, Jean. Les contrats de concession commerciale en droit français et communautaire, Paris: Sirey, 1968.

. La rupture abusive des contrats à durée indéterminée. In: La tendance à la stabilité du rapport contractuel. Paris: LGDJ, 1960.

JAMIN, Christophe. Plaidoyer pour le solidarisme contractuel. In: Mélanges Ghestin. Paris: LGDJ, 2001. p. 444-472.

JUNQUEIRA DE AZEVEDO, Antonio. Contrato de distribuição - causa final dos contratos de trato sucessivo - resilição unilateral e seu momento de eficácia - interpretação contratual - negócio per relationem e preço determinável - conceito de "compra" de contrato e abuso do direito. Revista dos Tribunais, São Paulo, v. 826, p. 119-136, 2004.

LICARI, François Xavier. La protection du distributeur intégré en droit français et allemand. Paris: Litec, 2002.

MARTINEK, Michael; SEMLER, Franz-Jörg; HABERMEIER, Stefan. Handbuch des Vertriebsrechts. 2. ed. München: Verlag C. H. Beck, 2003.

MARTINS-COSTA, Judith. A boa-fé no direito privado. Revista dos Tribunais, São Paulo, 1999.

. A boa fé objetiva e o adimplemento das obrigações. Jurisprudência Brasileira, São Paulo, p. 11-36, 2000.

MAZEAUD, Denis. Durées et ruptures. RDCO, v. 1, p. 129-147, 2004.

. Loyauté, solidarité, fraternité: la nouvelle devise contractuelle? In: Mélanges Terré. Paris: Dalloz, 1999. p. 603-634.

MESTRE, Jacques. Résiliation unilatérale et non-renouvellement dans les contrats de distribution. In: La cessation des relations contractuelles d'affaires. Paris: PUAM, 1997.

. D'une exigence de bonne foi à un esprit de collaboration. Revue Trimestrielle de Droit Civil, Paris, p. 100-125, 1986.

MONTEIRO, António Pinto. Contratos de agência, de concessão e de franquia ("franchising"). Boletim da Faculdade de Direito da Universidade de Coimbra, n. esp.: Estudos em homenagem a Eduardo Correia, p. 303-327, 1984.

. Contratos de distribuição comercial. 2. ed. Coimbra: Almedina, 2004. 
MOUSSERON, Jean-Marc et al. Droit de la distribution. Paris: Litec, 1975.

. Producteurs, distributeurs, quelle concurrence? Paris: Litec, 1986.

NANNI, Giovanni Ettore. O dever de cooperação nas relações obrigacionais à luz do princípio constitucional da solidariedade. In: Temas relevantes do direito civil contemporâneo. 1. ed. São Paulo: Atlas, 2008. p. 283-321.

NEGREIROS, Teresa. Fundamentos para uma interpretação constitucional do principio da boa-fé. Rio de Janeiro: Renovar, 1998.

OERTEL, Roberta Ribeiro. La détermination de la juridiction compétente du contrat international de concession exclusive. L'observateur de Bruxelles, Bruxelas, n. 98, p. 36-38, out. 2014.

PAOLA, Leonardo Sperb de. Sobre a denúncia dos contratos de distribuição, concessão comercial e franquia. Revista Forense, São Paulo, v. 343, n. 94, p. 116-148, 1998.

POLLAUD-DULIAN, Frédéric; RONZANO, Alain. Le contrat-cadre, par-delà les paradoxes. Revue Trimestrielle de Droit Commerciale, Paris, 1996.

REQUIÃO, Rubens. O contrato de concessão de venda com exclusividade (concessão comercial). Revista de Direito Mercantil, Rio de Janeiro, v. 7, p. 16-45, 1972.

RIZZO, Frédéric. Regards sur la prohibition des engagements perpétuels. Droit et Patrimoine, n. 78 , p. 60, 2000.

RUBINSTEIN, Flávio. A bona fides como origem da boa-fé objetiva do direito brasileiro. Revista da Faculdade de Direito da Universidade de São Paulo, São Paulo, v. 99, p. 573-658, jan./dez. 2004.

SAYAG, Alain (Org.). Le contrat-cadre, 2: la distribution. Paris: Litec, 1995.

. La moralisation des contrats de distribution par la loi Doubin du 31 décembre 1989 (art. 1er). JCP E, II, 15809, p. 7-25, 1990.

STOFFEL-MUNCK, Philippe. L'abus dans le contrat. Paris: LGDJ, 2000.

STRENGER, Irineu. La notion de lex mercatoria en droit de commerce international. Recueil des Cours de l'Académie de Droit International de La Haye, Haia, t. 227, p. 209-335, 1991-II.

TOURNEAU, Philippe Le. Les contrats de franchisage. Paris: Litec, 2003.

. Le droit de la responsabilité et des contrats. Paris: Dalloz, 2002.

VASCONCELOS, Pedro Pais de. Contratos atípicos. Coimbra: Almedina, 1995.

VIGNAL, Malaurie. Droit de la distribution. Paris: Sirey, 2012.

VIRASSAMY, Georges. Les contrats de dépendance. Paris: LGDJ, 1986.

WALD, Arnold. Le droit brésilien et le Code civil 2002. In: Wald, Arnold (Org.). Code civil brésilien. Société de Législation Comparée, 2009. p. 22-47. 